\title{
LAMBA, XAVACA, MORADAMA, tres topónimos en Sierra Elvira (GRANADA)
}

La doble vertiente románico-semítica de la Toponimia granadina ha quedado bien perfilada en una serie de trabajos, desde los ya lejanos de Simonet ${ }^{1}$ y Gómez. Moreno ${ }^{2}$, hasta los nús recientes de Seco de I ucena ${ }^{3}$. I a peculiaridad del habla gianadina ya fue scrialacla por el tunecino Ibn Jaldūn ${ }^{4}$, que estuvo en Granada en $1362-65$, y huego cn 1374. Hay noticias de que en I3II entre los 260.000 musulmanes que vivian en Granada no se hallaban 500 que fuesen moros de raza, el resto de la población eran hijos o nietos de cristianos (Simonet, Historia, p. 792) ${ }^{5}$. I, a convivencia cristiano-islámica granadina se refleja en el Vocabulista aravigo en lengua castellana, escrito a raíz de la reconquista (I492) por Fr. Pedro de Alcalá 6; resulta, pues, muy lógico que la Toponimia granadina sea un testimonio más de la mencionada simbiosis.

1 F. J. Simoner, Glosario de voces ibéricas y latinas usadas entre los mozarabes, Madrid, $x 888$.

F. J. Srmoner, Descripción del reino de Granada bajo la dominación de los Naseritas, sacada de autores árabes, y seguida dcl texto inédito de Moinammed Ebn Aljathib, Madrid, 1820 .

2 Nos referimos a una serie de estudios de historia y arqueologia, de Mañer. Gómez-MORINo y MARTiñz, que recogen valiosos testimonios sobre toponimia granadina recogidos en Misceláneas. Historia. Arte Arqueologia. Prinera Serie: La Antigïedad. Madrid, C. S. I. C., 1949, y especialmente el estudio La Alpujara en $A l$-Andalus, I95 I, XVI, pp. I7-36.

3 I. SECO DE LUCENA, Estudios sobre toponimia árabe granadina, publicados en $A l$-Andalus desde el año I944 (Al-Andalus, I944, IX, pp. 508-507. Véase el Indice de $A l$-Anlalus.

- IBN JAI,DUN. Prolegomenes historiques d'Ibn Khaldonn, III, en Notices et extrails des manuscrits de la Bibl. Impériale, tomo XXI, París, I868, p. 423.

- F. J. Simonex, Historia de los mozárabes de España, Madrid, 1897-1903.

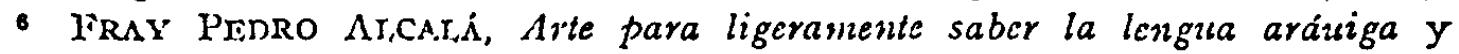
Vocabulista arduigo en lengua castellana, Granada, 1505.

20 
El Libro de Apeos de 1 tarfe ${ }^{1}$, fechado en I572, recoge, entre otros, los siguientes topónimos:

LAMBA: 1 "E yendo por el camino del Soto de Roma adelan-1 te se llegó a donde se junta el camino ${ }^{1}$ de Granada, que se donde se dezía la Lanba ${ }^{1}$ de Guécar, que quicre dezir la buelta de ${ }^{1}$ Gucear...*

XAVACA Y MORADAMA: "Pagos de Xavaca y la Moradama. Dos pagos, incorporados el uno con el otro, de ricgo y liazas calmas. Por una parte alindan con la carrera baja que va de $\Lambda$ tarfe a Santafé, por otra parte con el camino del Soto, y con el camino que va del fresno gordo a Pinos, el dicho camino llega hasta la dicha carrera, doude se comenzó a deslindar.

Iil deslinde se hizo 2 r-25 de junio de 1572 , y los moriscos tenian en estos dos pagos 1.300 marjales de riego.

La identificación de los topónimos mencionados no resulta empresa difícil teniendo en cuenta las referencias minuciosas del Apeo, con señalamiento de acequias, caminos, accidentes del terreno, muchos de los cuales han conservado su antigua fisonomía. Fil mapa adjunto señala la posición de los topónimos en el $\Lambda_{1}$ co de $\mathrm{I}_{57^{2}}{ }^{2}$. Como podemos apreciar. lamba, cscrito tanbićn lanba, se sitúa en terreno que continúa sicudo, y que en otro tiempo fue, lugar de ciénaga, lodozal, terreno embarrado. Resulta evidente su relación con cl latín lama "ciénaga, lodozal», máxime cuando tenemos constancia de dicha palabra, como mazarabismo, en el árabe granadino, lamách "encenagamiento» y lanmách "encenagar» y mulaminách «ulodoso», en P. Alcalá (Corominas, DCELC, III, I9) ${ }^{3}$. De todas formas en I57\%, en el momento de redactar el Apeo, los dos vecinos y conocedores del lugar, consideran necesario aclarar el significado del topónimo la lamba de huécar conl la expresión "que quiere dezir la buelta de Huécary 4 .

1 Apeo de el lugar del Atarfe hecho por el Lizenciado Pedro de Herreva ante Alonso Jaramillo, escrianno, año de 1572. Libro mauuscrito que se conserva en el Archivo de la Real Chancillería de Granada. Contiene además un traslado de 17 de de junio de 1572 , y otro de 16 de julio de 1593 .

$2 \mathrm{Ml}$ agradecimiento a todos los vecimos de Atarfe que, de algúu modo, me lian ayndado en la identificación de los topónimos sobre el terreno, y uny especial a D. José Osuna Jiménez, farmacéutico de Atarfe y experto en noticias y tradiciones locales, que durante muchos años ha ido recogiendo una especie de Memorial.

3 J. Coronanas, Diccionario critico etimologico de la lengua castellana, 4 vols. Madrid, I954.

- Los escribauos del siglo xiI tuvieron que valerse de intérpretes de la lengua arábica, tanto en la averiguación de los bienes abandonados por los moriscos, cowo en la interpretación de los nombres de lugar. Eran variadas las fórnulas expresivas con que se introducian los arabismos. La fóruula "que se dize", "que dizen", "que es", se empleaba en arabismos de menor difusión. En este grupo está 


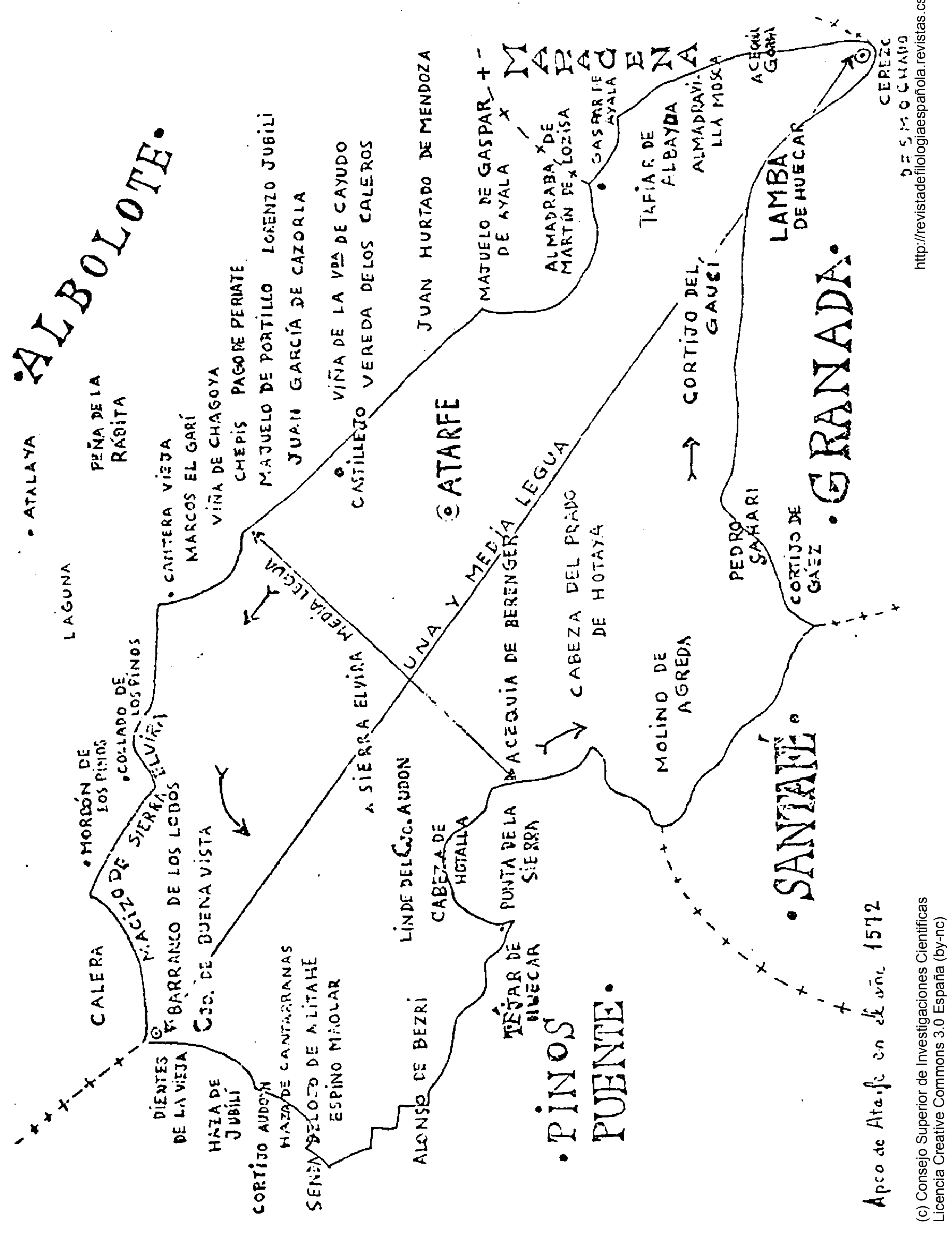


La ubicación del topónimo xavaca, según los testimonios del citado I,ibro de Apeos y los datos de primera mano recogidos' en el lugar, se sit:ia en una zona abundante en pozos. Ya el Diccionario geográfico de P. Madoz ${ }^{2}$, editado en I845, ofrece el testimonio de la existencia, en $\Lambda$ tarfe, de unos cien poz.os, con los que se surtían las casas y los abrevaderos de ganados, completando el suministro de agua de riegro proporcionado por la Acequia Gorda (saljja alkubra). En árabe š á b a c a : "terreno donde hay muchos pozos", "upozos cercanos", confirma el nombre del topónino registrado en el Apeo del siglo xVI ${ }^{2}$.

El topónino moradana aplicado a tierra de cultivo, de riego y hazas calınas, se puede relacionar con el ár. $\mathrm{r}$ a d a $\mathrm{m} \mathrm{a}$, ulabrar la tierra", y el derivado $\mathrm{m}$ u r a ç a in a, ár. vulgar moradama "labrantín. Resulta sorprendente que un topónimo tan relacionado con la vida agrícola y con especial característica de la vega de Granada, no se haya registrado liasta ahora en los estudios de toponimia granadina. No figura en índices de topónimos de los libros Habices, hasta ahora editados ${ }^{3}$, ni en cstudios generales de toponimía árabe, como los de Asín Palacios ${ }^{4}$ y Vernet 5 .

I,os pagos que visitó el 3 de julio de I572 $^{2}$, el licenciado Herrera, acompañado de Diego García I,ópez y Juan I,ópez de Corpas, vecinos de Atarfe y conocedores del lugar, fueron: Pago de Elvira, Hotaya, Farfillaz, Xavaca, Moradama, Mararaufauqui, Majarguezlín, Daraçali, El Remil, Alabar, Maruan, I,a Mancoxa, Viñas de Atarfe; muchos de dichos nombres se fueron olvidando con el tiempo, y ya en el siglo xvirr, el Catastro del Marqués de la Ensenada ${ }^{6}$ consigna en el "Borrador de Tierras de Secano de Atarfen, los pagos siguientes: Almendral, Los Oli-

la expresión "que quiere dezir". Véase mi estudio Escritura bilingïe en el Reino de Granada (siglo VXI, seguin documentos incditos del Archivo de la Alhambra, Actas del Primer Congreso Internacional de Hispanistas, Oxford, 1964, pp. 371-374.

1 P. Madoz, Diccionario geogrdfico-estadístico-histórico de España y sus poscsiones de Ultramar, I6 vols. Madrid, 1845.

2 In el diccionario árabico-latino de G. W. FreYTAG, Lexicon ArabicoLatinusm, 4 vols. Halle, 1830-7, tomo 2, p. 390, sabaka, en plural = 'putei invicem propinqui, et foutes apparentes', y 'terra puteis abundans'.

s M.a DEL Carmen Vilianuteva Rico, Habices de las Mezquitas de la ciudad de Granada y sus alquerias. Edición, introducción e indices, Madrid, 1961.

Casas, mezquitas y tiendas de los Habices de los Habices de las Iglesias de Granada. Edición, introducción e indices. Madrid, 1966.

- M. Asin Palacios, Contribascion a la Toponimia Arabe de España. Madrid, 1944.

- J. VERNeT Gnes, Toponima arábica, en Enciclopedia Lingüistica Hispdnica, towo I, Madrid, I960, p.p 56I-578.

- Catastro del Marqués de la Ensenada, r752. 
vares, La Calerilla, Ias Canteras, Carril de Marugán, Cuesta de la Hermita, Hera de la Flermita de Santa Ana, Los Higuerales, Las Canteras Altas, Fuente Baxa de Marugán, Los Calerones, Fuente del Tesoro, Las Yeseras, Los Yesares, Las Yeserillas, Ilanadas de Marugán, Iras Zorreras, Cerro de lirías, Barranco de Jordán, Canteras Baxas, Pozos de las Canteras Baxas, del Palomar, de los Pozos, Las Ilanadas de Marugún, Cantarranas, Cueva de la Gallara, del Baño, Cueva del Rey; Cueva de 1a Higuera, Punta de la Sierra, La Paluchina, Tierras de la Hermita de Santa Ana.

Como podemos apreciar el nombre de Maruán, del pago del árabe MI a I wà $\mathrm{n}$, nombre propio de persona, se transforma en el Marugán del siglo xVIr, mientras que Xavaca figura como I,os Pozos, es decir, en su forma traducida del árabe al español. En un estudio fechado en I909, Manuel Gómez-Moreno ${ }^{1}$, al enumerar los caseríos romanos en la vega, señaló la población existente junto a los baños termales de Elvira, y el "cementerio bárbaro en Marugán", sólo comparable al de Ventas de Zafarrayan, por la abundancia y calidad de sus arreos".

Pensamos, por otra parte, que la vega y provincia de (iranada, tan abundante en toponimia romana, of rece muchas veces topónimos árabes que no son más que la traducción de los romanos preexistentes; asi Xavaca es la traducción árabe del romance Pozuelos (1at. putentii), y moradama puede responder a un labrantio. El caso de Xavaca convertido hoy en Los Pozos, nos ofrece un interesante ejemplo de desarabización y vuelta o regreso al étimo latino primitivo. En conclusión: los tres topónimos que acabamos de estudiar ofrecen la misma mezcla de rasgos mozárabes e hispanoárabes que los documentos granadinos del siglo XVI, relativos al secuestro de bienes, ceriso y otros asuntos relacionados con la vida de los moriscos del reino de C:ranada 2 .

Juan MarTí:iz Ruiz

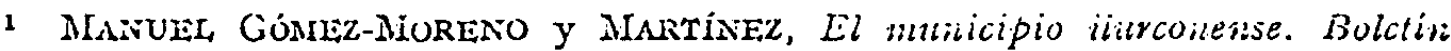
de la lieal Acadenizia de la Historia, L, p. I 72 y ss., reproducido eil pp. 3'jl-40I, de las citaclas Misculáne'ss. Hisloria-Arte-Arqueologia, véase, p. jo-r.

2 JUAN MARTintez RUiz, Diacronia y adstralo. Rasgos mazárazs e hispanodrabes en documentos granadinos del siglo XYI, en Actas del XI Congreso Internacional de Lingùistica y Filologia Románica. Bucarest, 1971, tomo II, pp. I.I 45 -I.I55. 